Portland State University

PDXScholar

1976

\title{
A Comparison of Two Articulation Management Approaches
}

Cindy Sue Sykes

Portland State University

Follow this and additional works at: https://pdxscholar.library.pdx.edu/open_access_etds

Part of the Speech Pathology and Audiology Commons Let us know how access to this document benefits you.

Recommended Citation

Sykes, Cindy Sue, "A Comparison of Two Articulation Management Approaches" (1976). Dissertations and Theses. Paper 1170.

https://doi.org/10.15760/etd.1169

This Thesis is brought to you for free and open access. It has been accepted for inclusion in Dissertations and Theses by an authorized administrator of PDXScholar. Please contact us if we can make this document more accessible: pdxscholar@pdx.edu. 
A COMPARISON OF TWO ARTICULATION

MANAGEMENT APPROACHES

by

CINDY SUE SYKES

Substantial papers submitted in partial fulfillment of the requirements for the degree of

\author{
MASTER OF SCIENCE IN SPEECH COMMUNICATION: \\ with an emphasis in \\ SPEECH PATHOLOGY/AUDIOLOGY
}

Portland State University

1976 


\section{ACKNOWLEDGMENTS}

To all who have had a part in my seven-year quest for this endeavor I express my thanks. No person has been more helpful to me than Mary E. Gordon, my project supervisor. Because of her sincere concern and the many hours of consultation and assistance she gave me, this project became a reality.

I thank my dear friend, Marilyn Anderson, for her encouragement and financial support these last few months.

To Janet and. Vance Burns I express my gratitude for so faithfully bringing to the clinic Keith and Kurtiss, the subjects of this study

And, lastly, my parents-only God knows how much their loving support has been an inspiration to me, not only for their monetary support but also for the many times I called home for reassurance and the many trips home, which were so needed as a time away from my academic commitments. 
TABLE OF CONTENTS

Page

ACKNOWLEDGMENTS . . . . . . . . . . . . . . . $\quad$.

LIST OF TABLES . . . . . . . . . . . . . . . . . $\quad$ v

LIST OF FIGURES . . . . . . . . . . . . . . . . . vi vi

\section{CHAPTER}

I INTRODUCTION AND PURPOSE . . . . . . . . . . . 1

Introduction .............. . . 1

Statement of Purpose . . . . . . . . . 2

II REVIEW OF THE LITERATURE . . . . . . . . . . 3

Auditory-Stimulus Method . . . . . . . 3

Evaluation

Intervention

Sensory-Motor Method . . . . . . . • •

Evaluation

Intervention

Comparison of Approaches . . . . . . . 13

III METHODS AND PROCEDURES . . • • • • • • • • 15

Subjects •. . . . . . . . • • • • • 15

Evaluation ................ . . 16

Management . . . . . . . . . . 16

Data Comparison . . . . . . . . . 17 
CHAPTER

IV RESULTS AND DISCUSSION . . . . . . . . . . 18

Results................. . . 18

Discussion ............... . . . 23

V SUMMARY AND IMPLICATIONS . . . . . . . . . . 27

Summary ................ . . 27

Implications . . . . . . . . . . . 28

REFERENCES CITED . . . . . . . . . . . . . . . 29

APPENDICES . . . . . . . . . . . . . . . . . . 30

A ....................... 30

В ....................... 31 


\section{LIST OF TABLES}

\section{Page}

\section{TABLE}

I TYPES OF SYLLABLES . . . . . . . . . . . . . . 9

II SUMMARIZATION OF BASIC FACTORS OF EACH TREATMENT APPROACH . . . . . . . . . . . . 14

III PRE- AND POST-TEST RESULTS FOR SUBJECT A (AUDITORY-STIMULUS METHOD) . . . . . . . . . . 19

IV PRE- AND POST-TEST RESULTS FOR SUBJECT B (SENSORY-MOTOR METHOD) . . . . . . . . . 20 


\section{LIST OF FIGURES}

Page

\section{FIGURE}

1 Subject A pre-test phonetic profile . . . . . . 21

2 Subject A post-test phonetic profile . . . . . . 21

3 Subject B pre-test phonetic profile . . . . . . . 22

4 Subject B post-test phonetic profile . . . . . • 22 
CHAPTER I

INTRODUCTION AND PURPOSE

\section{$\underline{\text { Introduction }}$}

Of the various disorders of speech and language, articulation appears to be the most frequent comprising 75 per cent of the disorders (Van Riper, 1972); articulation disorders, thus, pose a distinct challenge to the speech pathologist. Because individuals vary so much, many techniques for articulation management have been devised, e.g., auditory-stimulus, sensory-motor, distinctive feature, and motokinesthetic (Van Riper, 1972).

The auditory-stimulus method devised by Van Riper (1972) seems to be the most widely used approach. Auditory-stimulus is a treatment method which begins with ear training and proceeds to production in isolation, nonsense syllables, words, and meaningful sentences. Additionally, the misarticulated sounds are presented in initial, medial, and final positions.

McDonald (1964b) developed a treatment approach to articulation by implementing production of bisyllables, trisyllables, and sentences in systematically varied phonetic contexts. Initially treatment begins with the production of correctly articulated sounds in bisyllables with the client describing oral articulatory movements, and then proceeds to work on error sound or sounds in trisyllables, two-word combinations, and sentences. 
McDonald (1964b), however, has questioned the effectiveness of the traditional auditory-stimulus method. He posed the following considerations in his discussion of articulation intervention: 1) 0nly in words do sounds appear in the three positions of initial, medial, and final; 2) speech sounds do not exist in isolation; 3) using vowel letters in constructing nonsense syllables is not used in analyzing spoken speech; and 4) many children do not need to analyze the externally produced model by drilling with ear training procedures in which the child listens to the sound produced by another person rather than by his own speech mechanism.

It would seem that speech clinicians should consider implementing a sensory-motor approach for articulation management with at least some articulation disordered clients.

\section{Statement of Purpose}

This clinical project sought to examine two different approaches to the treatment of functional articulatory disorders and to implement these two approaches in the actual management of two articulation disordered clients. The two approaches selected were the traditional auditory-stimulus method (Van Riper, 1972) and the sensory-motor approach (McDonald, 1964b) to testing and treatment. It was the intention of this project to compare the results of articulation intervention of the two methods. 
CHAPTER II

REVIEW OF THE LITERATURE

\section{Auditory-Stimulus Method}

One of the most widely used articulation management approaches was devised by Van Riper (1972). This approach, the auditory-stimulus (A-S) method, basically uses auditory and visual stimuli to elicit the target sound in isolation, nonsense syllables, words, and meaningful sentences. Relative to his approach, Van Riper (1972) indicates causal factors for each individual client may indicate deviation from the outlined auditory-stimulus program. For some clients, the clinician may choose to omit any one of the steps or procedures of management if the client already demonstrates proficiency, e.g., ear training or production in isolation. In addition, for elicitation of a target sound it may be necessary to use techniques other than auditory and visual stimulation, such as phonetic placement, distinctive features, or a "key word" method.

According to Van Riper (1972), the first responsibility of a clinician using the A-S method is to convince the client he does not speak correctly; it is not enough simply to call attention to the error. The clinician then must help the person "unlearn" the error pattern by teaching him to produce the correct sound. The learning process thus requires goal setting in terms of target sounds. By weakening and extinguishing incorrect responses, the clinician helps the child 
acquire and strengthen new responses.

Van Riper (1972) further emphasizes it is the clinician's responsibility to establish a close relationship with the client, provide positive reinforcements, and create situations in which learning can occur by providing a correct model. Of paramount importance is the clinician's responsibility to know where the child is, where he has been, and where he has to go in treatment.

\section{Evaluation}

Articulation testing, according to Van Riper (1972), is a vitally necessary task in dealing with persons with misarticulations. The clinician must determine the answers to the following questions:

1) What are the articulation errors? 2) How many errors are there?

3) What types of errors are there? and 4) How consistent are the errors? In other words, understanding or diagnosing an articulation deviant client must consist of a phonetic analysis of speech in terms of 1) the sounds which are defective, 2) the type of error, i.e., substitution, omission, addition, or distortion, 3) the location of the error within the word (initial, medial, or final positions), 4) the number of errors, and 5) the consistency of the errors. In addition to a phonetic analysis, a kinetic analysis is done. It is important to know how the misarticulated sounds are being misproduced (manner of production).

\section{Intervention}

After the client is convinced he has a speech error and before he produces the target sound, ear training is implemented. The child must 
demonstrate he can hear the sound as a distinct unit. In order for the client to acquire the concept of a standard sound, one against which he may later match his own utterance, four basic levels of auditory discrimination are presented: 1) isolation, 2) stimulation, 3) identification, and 4) discrimination. All of these levels help define the target sound. The child first internalizes the model or standard sound by listening to the model in isolation and in meaningful words and sentences. Secondly, he scans and compares his own production with the model (self-hearing). Later in self-hearing a dimension of time is added: The child recognizes his errors 1) after they have occurred (recalling), 2) when they are occurring (perceiving), and 3) before they occur (predicting).

Upon completion of ear training, the child produces the correct sound in 1) isolation, 2) nonsense syllables, 3) words, and 4) meaningful sentences.

Making the Sound in Isolation. Production of the isolated sound begins with repeated auditory and visual stimulation of the child as the clinician articulates the sound in isolation. The child "learns" the sound by hearing it, then imitating it. While imitating the sound, he observes his own speech mechanism in a mirror.

Making the Sound in Nonsense Syllables. After the sound is correctly produced in isolation with consistency, it is combined with vowels /e, i, u, o, $\boldsymbol{e}, \mathrm{a}, \boldsymbol{\varepsilon}, \boldsymbol{v}, \mathrm{I}, \wedge /$ to form syllables. The clinician again gives repeated auditory and visual stimulation. The sound is produced in syllables in the following positions: 1) initial (cv), 2) medial (vcv), and 3) final (vc). 
Making the Sound in Words. The sound is next articulated in familiar, simple words. Again it is used in words in the initial, medial, and final positions.

Making the Sound in Sentences. Finally, the target sound is emitted in sentences. It is at this level that production should become automatic for carry-over.

Within each of the four operational levels described above, the child must attain the following skills at each of these levels:

1. Identifying the errors and the standard pattern of the sound.

2. Scanning and comparing his own utterance with the standard.

3. Varying his utterance until the correct sound production is achieved.

4. Stabilizing and habituating his new correct ways of speaking so they can be used automatically (Van Riper, 1972).

\section{Sensory-Motor Method}

McDonald (1964b) bases his articulation management program on a sensory-motor approach. He explains:

Articulation is a process consisting of overlapping, ballistic movements which place varying degrees of obstruction in the way of the outgoing air stream and simultaneously modify the size, shape, and coupling of resonating cavities.

Articulation, then, is viewed as one of several interrelated processes by which speech is produced.

According to McDonald (1964b), a physiologically oriented definition of speech provides the most effective basis for developing 
rationales for the treatment of articulatory defects. He uses Stetson's (1951) definition of speech as "a series of movements made audible." The movements must be activated, monitored, and controlled. Thus, when speech is defective, the movements which produce it also must be defective in some way.

He has classified three types of movements which occur in articulation: 1) fixed, 2) controlled, and 3) ballistic. A fixed movement is one in which antagonist and agonist muscles are contracted in balance resulting in the structure being held in a fixed position, as when the arm is raised to shoulder height and held there. A controlled movement is achieved when one muscle group is contracted more than another muscle group. For example, when one attempts to trace a circle, being careful not to get off the line, he employs controlled movements. The muscles which move the pencil forward around the circle are held in check by those which would pull the pencil backward. A ballistic movement is begun with a quick contraction of the agonist (positive) muscle group, followed by a period of no contraction when the structure moves through its own momentum, followed by a stoppage of movement by the antagonist muscle group, e.g., picking up an object. All skilled movements are ballistic.

In addition to the three types of articulatory movements described above, the movements of articulation are overlapping, meaning there are simultaneous contractions of muscles. Because of these overlapping articulatory movements, the characteristics of any sound will be influenced by its phonetic context. Three types of overlapping movements are described by McDonald: 1) of different portions of the same organ 
(ask), 2) of different organs adjacent to each other (campstool), and 3) of different organs remote from each other (equipment). The /pm/ in the last example represents a fourfold overlapping movement involving the lips, the nasal port, the laryngeal muscles, and the mandible.

McDonald (1964b) further explains that speech sounds are the result of modifications of a mass of air which passes from the lungs through the laryngeal, pharyngeal, oral, and nasal cavities. Speech is produced in the exhalation phase of respiration by a series of pulses which correspond to syllables.

McDonald adheres to Stetson's (1951) theory of syllable production. He describes and identifies the following syllable components: 1) release, 2) vowel shaping, and 3) arrest. Syllables may be released either by action of the chest muscles operating alone or with consonant movement occurring in the oral cavity. In either case, the syllable is released into the vocal tract which has been appropriately shaped. Arresting of syllables may be achieved either by chest muscles alone or with a consonant movement. The consonant movement is always an auxillary movement to the vowel; a consonant only functions in a syllable. A vowel movement must be made by a releasing and an arresting pulse from the chest. The vowel, then, functions in articulation to shape the vocal canal for the chest pulse. The consonant is an articulation which functions to delimit the chest pulse of the syllable. Table I illustrates the four types of syllables which McDonald describes. Arresting consonants add to the duration of the syllable, while releasing consonants do not add to the duration of the syllable. A vowel or consonant functions to emit the syllable with a specific 
TABLE I

TYPES OF SYLLABLES

\begin{tabular}{cc}
\hline Syllable Type & Example \\
\hline OVo & $/ \mathrm{a} /$ \\
CVo & $/ \mathrm{ta} /$ \\
OVC & $/ \mathrm{at} /$ \\
CVC & $/ \mathrm{tat} /$ \\
\hline
\end{tabular}

$0=$ chest release, chest arrest

$\mathrm{C}=$ consonant release, consonant arrest

$\mathrm{V}=$ vowel shaping

quality and to make audible the releasing and arresting factors of the syllable. Resonance seems to be the most important factor for vowels; whereas, consonants seem to be a result of the interaction between the nature of tone by obstructing the vocal tract and the cavity which transmits it.

According to McDonald (1964b), three types of consonants may be identified:

1. Simple: A single consonant which serves to release or arrest a syllable as the $/ t /$ releases the syllable/ti/ or arrests the syllable/it/.

2. Compound: A group of two or more consonants which function as a single consonant, i.e., to release or arrest a syllable. They are intrasyllabic as the /st/ in "step" and in "lost."

3. Abutting: Adjacent consonants which are different sounds, one of which arrests the first syllable and the other of which releases the following syllable. They are intersyllabic as the /st/ in "history." 
In summary, the movements of articulation are superimposed on the syllable which in turn are imposed through exhalation. Articulatory events do not occur as isolated phenomena, but rather as auxillary movements in the syllable. Speech as well as motor activities develop from simple to complex.

\section{Evaluation}

McDonald's (1964b) theory of articulation production has influenced his development of an articulation evaluation procedure. He believes it is impossible to teach the "separate sounds" of a language, then to assemble them into syllables (syllables are not assemblies), and then to add proper stress, pauses, and intonation (they are not additions but basic components). According to McDonald, the following principles must be understood and considered in testing articulation ability:

1. Articulation is one of several processes involved in the production of speech which, in turn, is one of several modalities through which language is employed.

2. Speech is a series of movements made audible.

3. Three kinds of movements may be employed in speaking: fixed, controlled, and ballistic.

4. Physiologically speaking, the syllable is the morphologic unit of speech and articulatory movements are auxillary movements in the syllable.

5. In producing a sequence of speech sounds, the movements of articulation are overlapping.

6. Articulation skills develop from simple to complex as a result of the interaction of maturing sensorymotor processes. 
Application of these concepts leads to criticisms of the classical three-position testing procedures (initial, medial, and final):

1. It is word oriented and words do not appear in speech as entities, but only as a sequence of syllables.

2. Consonants do not appear in initial, medial, or final positions in speech. They exist as auxillary movements in the syllable and function as releasors and arrestors of the syllable.

3. The sampling of phonetic contexts, and consequently the movement sequences, is accidental rather than systematic.

4. Physiologically speaking, there are three types of consonants: simple, compound, and abutting. Abutting consonants create many contexts which require unique and complex movement sequences. The three-position test does not provide opportunities to observe the child's ability to perform these movements.

Relative to articulation assessment, McDonald (1964b) summarizes as follows:

An approach to assessing articulation which permits the evaluation of a speech sound as an audible end product of a series of overlapping ballistic movements, which enables the tester to observe the influence of a variety of phonetic contexts on the articulation of the sound, and which is feasible in terms of administration time can be constructed by presenting each sound as preceded by each other sound and followed by a vowel, and as followed by each of the other sounds and preceded by a vowel.

McDonald (1964b) has constructed two tests for evaluating articulation skills: 1) a screening test, and 2) a deep test consisting of a picture form and a sentence form. 
The screening deep test provides the speech clinician with a tool which permits quick observation of a child's articulation of several commonly misarticulated consonants in a variety of phonetic contexts. The test is composed of ninety bisyllable items which sample the child's ability to articulate consonants in connected syllables and which discriminatively detect those phonemes which are misarticulated. The bisyllables also sample the child's ability to articulate consonants in connected speech. In some bisyllables the clinician evaluates the articulation of two consonants; in others, three consonants; and in a few, four consonants. Recently, norms have been developed for beginning kindergarten through beginning third grade students to aid in interpretation of the screening test (McDonald and McDonald, 1974).

The deep test uses monosyllabic words consisting of twenty-five consonants and ten common vowels of English speech to test the influence of a variety of phonetic contexts on the articulation of the sound. From the use of the screening test, the defective sound or sounds will be deep tested in approximately thirty contexts. A picture form and a sentence form are available for deep testing.

Logically, it would seem this systematic variation of the phonetic environment in which the sound is articulated would yield a representative sampling of the movement patterns by which the phoneme under study is produced.

Intervention

The aim of McDonald's approach to articulation intervention is to help the child learn to articulate his error sound correctly in system- 
atically varied phonetic contexts through three procedures. The first procedure is to heighten the client's responsiveness to the patterns of auditory, proprioceptive, and tactile sensations associated with the overlapping ballistic movements of articulation. To accomplish this bisyllables and trisyllables of varying stress are imitated and described by the child. Additionally, he is asked to describe which two articulators touch and to describe the direction of tongue movement. The second procedure is to reinforce the child's correct articulation of his error sound. The third procedure is to facilitate the correct articulation of the error sound in systematically varied phonetic contexts; auditory stimuli are presented which the child is instructed to duplicate. The client modifies the movement patterns which have produced a satisfactory sound by changing the vowel following the sound until the correct movement sequences for that sound have developed with several vowels. The client, then, combines a word with words beginning with that sound, but selected to have the sound followed by several of the vowels. And lastly, the child practices modifying the context in additional word combinations and sentences.

\section{Comparison of Approaches}

There are basic differences between the auditory-stimulus and sensory-motor approaches to articulation management. McDonald (1964b) bases his approach on the whole speech process as a motor activity and considers the phonetic environment. Van Riper (1972), on the other hand, views articulation relative to auditory stimulation and does not consider phonetic contexts other than in the three word positions. 
Table II summarizes the basic differences between the two approaches.

\section{TABLE II}

SUMMARIZATION OF BASIC FACTORS OF

EACH TREATMENT APPROACH

Van Riper

McDonald

Uses ear training in

treatment.

Bases management on the three positions: initial, medial, and final.

Initial production is of the error sound.

Actual production begins with the isolated sound.

Does not vary stress patterns in management.

Articulatory movements are visually and auditorally stimulated.

Does not systematically vary the phonetic environment of the target sound.
Does not use ear training in treatment.

Bases management on the releasing and arresting positions.

Initial productions are of sounds the client already produces correctly in at least one context.

Actual production begins with bisyllables.

Systematically varies. stress patterns in management.

Articulatory movements are verbally described by the client.

Systematically varies the phonetic environment of the target sound. 


\section{CHAPTER III}

\section{METHODS AND PROCEDURES}

\section{Subjects}

Twin males from Molalla, Oregon, were selected as the subjects for this clinical research project. At the time of pre-testing their ages were five years, one month.

Each subject displayed an articulation disorder as diagnosed by an elementary school speech pathologist. Neither subject had previously received any speech or language management. Subject A demonstrated normal hearing acuity as determined by pure tone audiometric screening at $20 \mathrm{~dB}$ for the frequencies of $500 \mathrm{~Hz}, 1000 \mathrm{~Hz}, 2000 \mathrm{~Hz}$, and $4000 \mathrm{~Hz}$ in both ears. Subject $B^{\prime}$ s pure tone thresholds in the speech frequencies $(500,1000$, and $2000 \mathrm{~Hz})$ for the right ear were within normal limits and were $25 \mathrm{~dB}, 25 \mathrm{~dB}$, and $30 \mathrm{~dB}$ for the left ear, respectively. His bone conduction thresholds were within normal limits, which is consistent with a mild conductive-type loss. Because of normal hearing in the right ear, client $B^{\prime}$ 's performance in a clinical management session would not be affected by the mild conductive-type loss in the left ear. Neither subject had any physical or organic anomalies as determined by the diagnostic evaluations at Portland State University Diagnostic Intake Clinic. Each subject demonstrated a language age equivalent six to nine months below his chronological age. 


\section{$\underline{\text { Evaluation }}$}

A brief case history dealing specifically with speech development was provided by the subjects' mother. The Utah Test of Language Development (Mecham, Jex, and Jones, 1967) was administered prior to treatment to establish a language age equivalent. The Hejna Developmental Articulation Test (He jna, 1955), A Screening Deep Test of Articulation (McDonald, 1968), and The Deep Test of Articulation (McDonald, 1964a) for / $f$ / were administered to the subjects prior to and upon completion of the management program. Two additional pre- and post-tests were administered, the first a two-minute conversation sample; in the second test the subjects were to repeat a list of twenty words containing the misarticulated sound. These pre-and post-tests were tape recorded.

The initial evaluation procedures were administered in two fiftyminute sessions at Portland State University Clinic. The post-testing evaluation was completed during the last session. The subjects' responses were tape recorded during evaluation sessions for later reference in analyzing articulatory performance.

\section{Management}

Each subject was enrolled in an articulation program for the $/ f /$ sound for forty-five-minute sessions twice weekly for six weeks. Subject $A$ received the auditory-stimulus method and Subject $B$ received the sensory-motor method. Appendices A and B outline the subjects' management objectives. 


\section{Data Comparison}

First, the percentage of correct responses for each pre- and post-measurement was computed. Then the two articulation management approaches were compared, using the changes in pre- and post-articulation test scores and the list of twenty words containing the $/ f /$ sound. These changes were finally calculated by dividing the increase of correct responses by the total possible increase. 


\section{CHAPTER IV}

\section{RESULTS AND DISCUSSION}

\section{$\underline{\text { Results }}$}

The purpose of this clinical project was to examine two different approaches for the management of functional articulatory disorders and to implement these two approaches in actual management of two articulation disordered subjects. Twin male subjects were selected, aged five years, one month, at the time of pre-testing, with Subject A receiving the auditory-stimulus method and Subject B receiving the sensory-motor method for treatment of articulatory disorders. Results for this clinical project were obtained by comparing the scores of pre- and posttests and then calculating changes by dividing the increase of correct responses by the total possible increase.

Pre- and post-test results and per cent of change for Subject A, who was on the auditory-stimulus articulation program, are shown in Table III. Table IV illustrates pre- and post-test results and per cent of change for Subject B, who was on the sensory-motor articulation program. Figures 1 and 2 illustrate the pre- and post-test phonetic profiles of Subject A; Figures 3 and 4 illustrate the pre- and post-test phonetic profiles of Subject B. These profiles were extrapolated from A Screening Deep Test of Articulation (McDonald, 1968). 


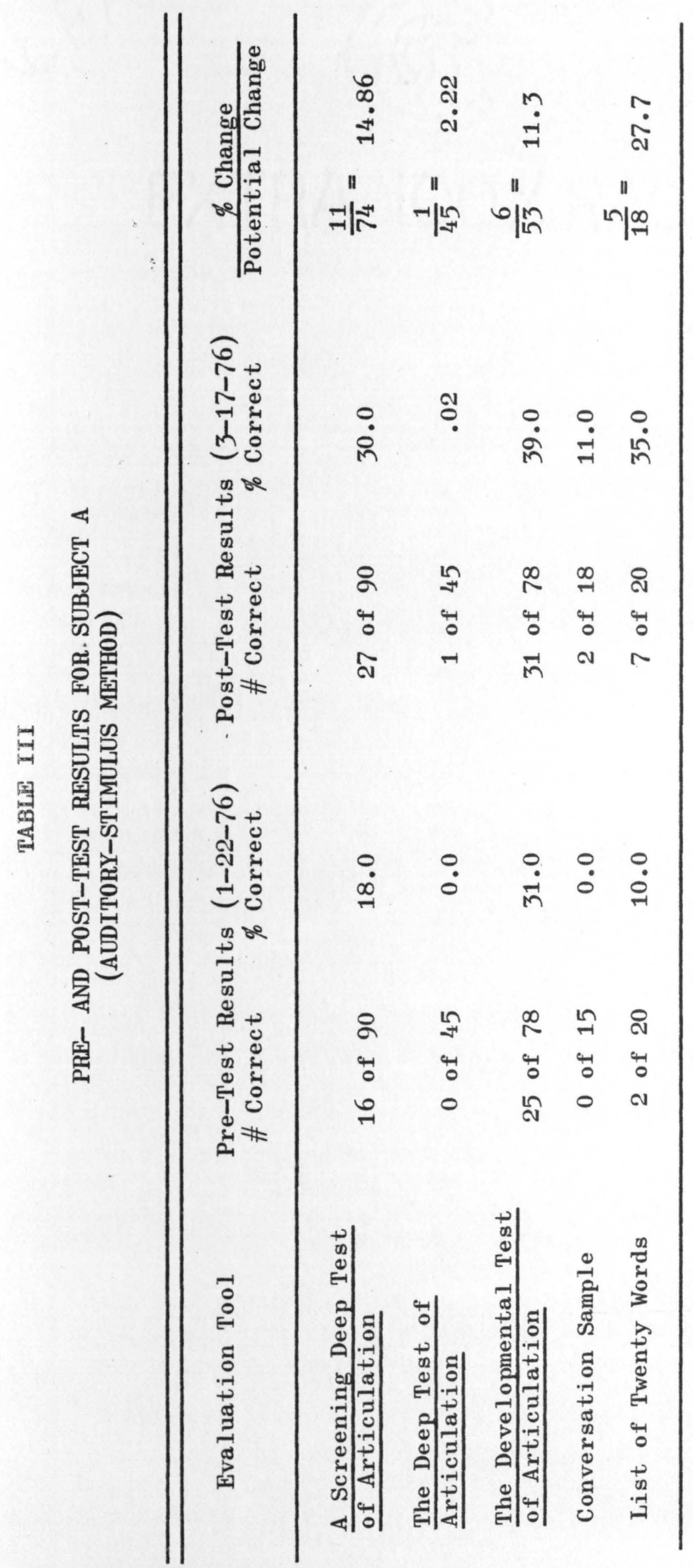




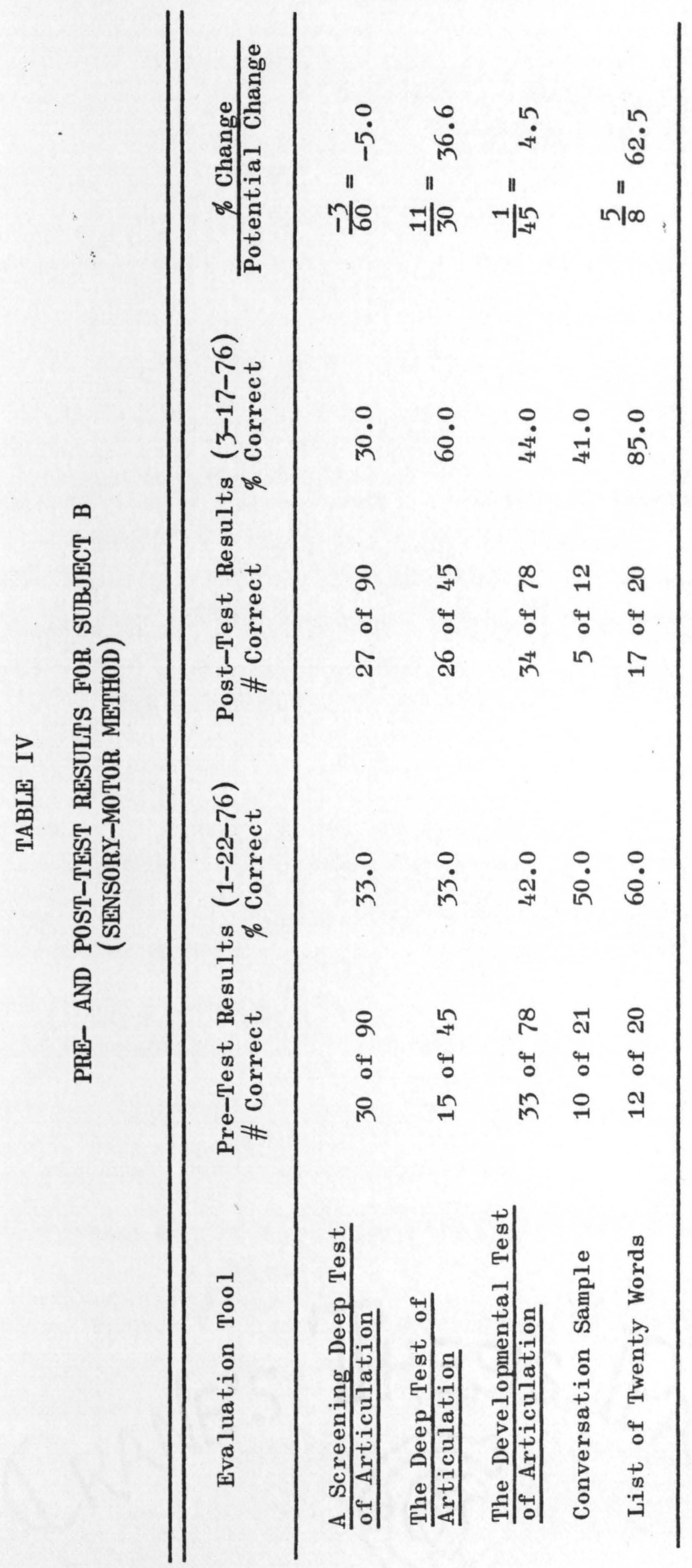




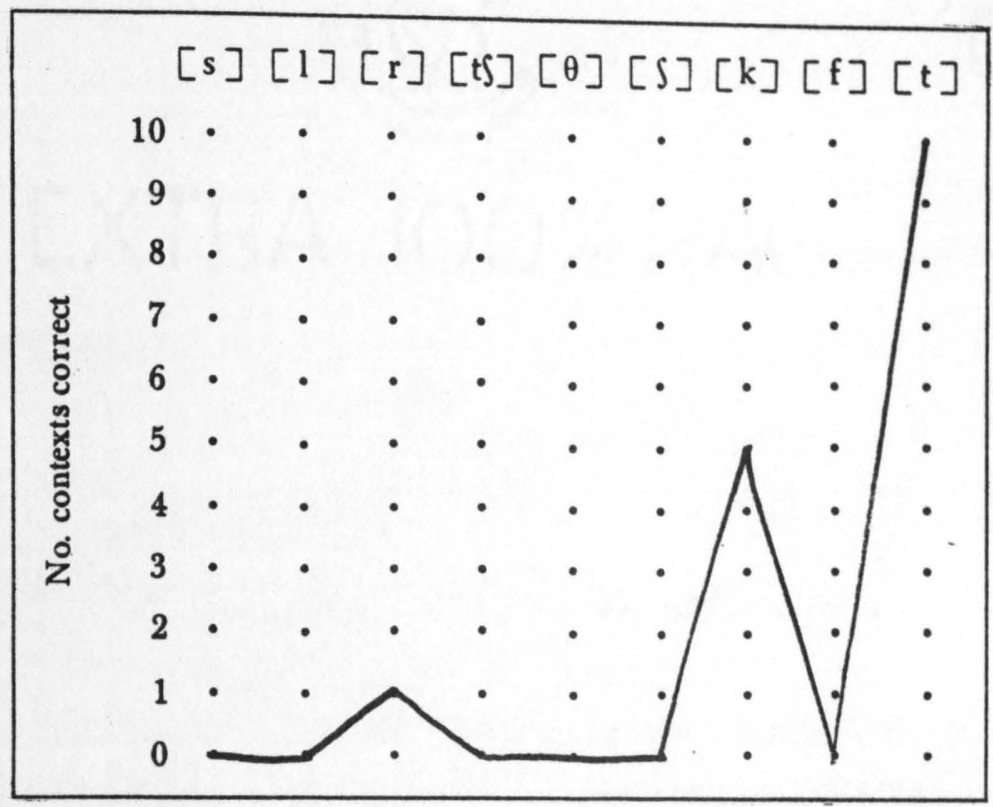

Figure 1. Subject A pre-test phonetic profile.

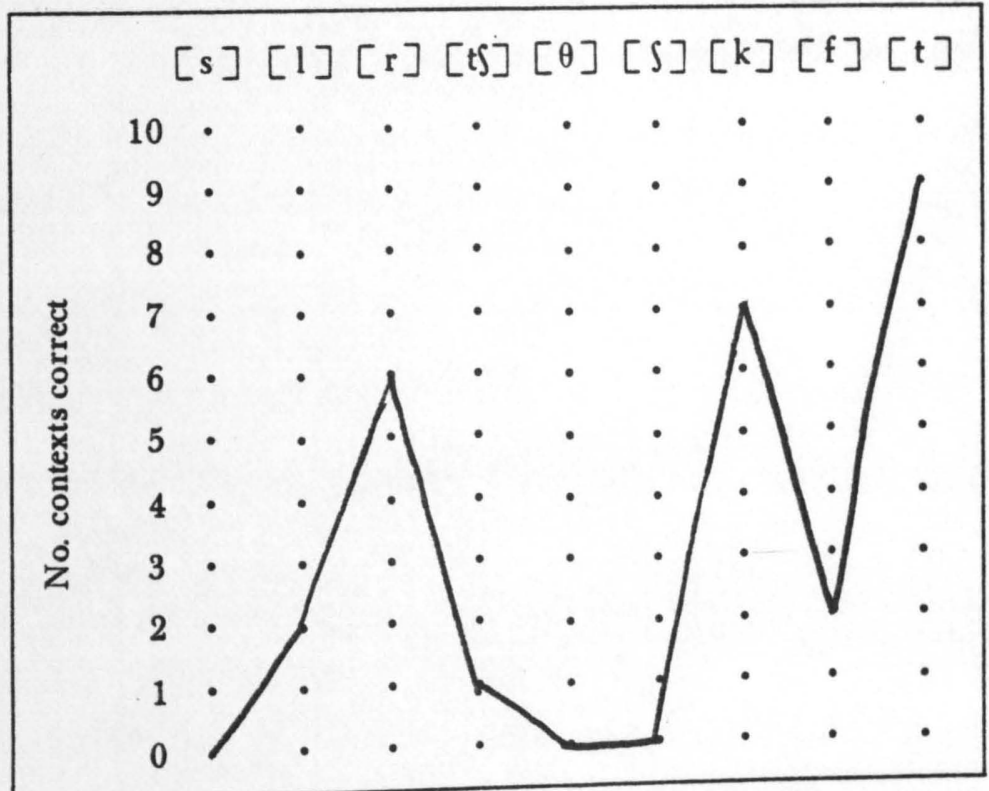

Figure 2. Subject A post-test phonetic profile. 


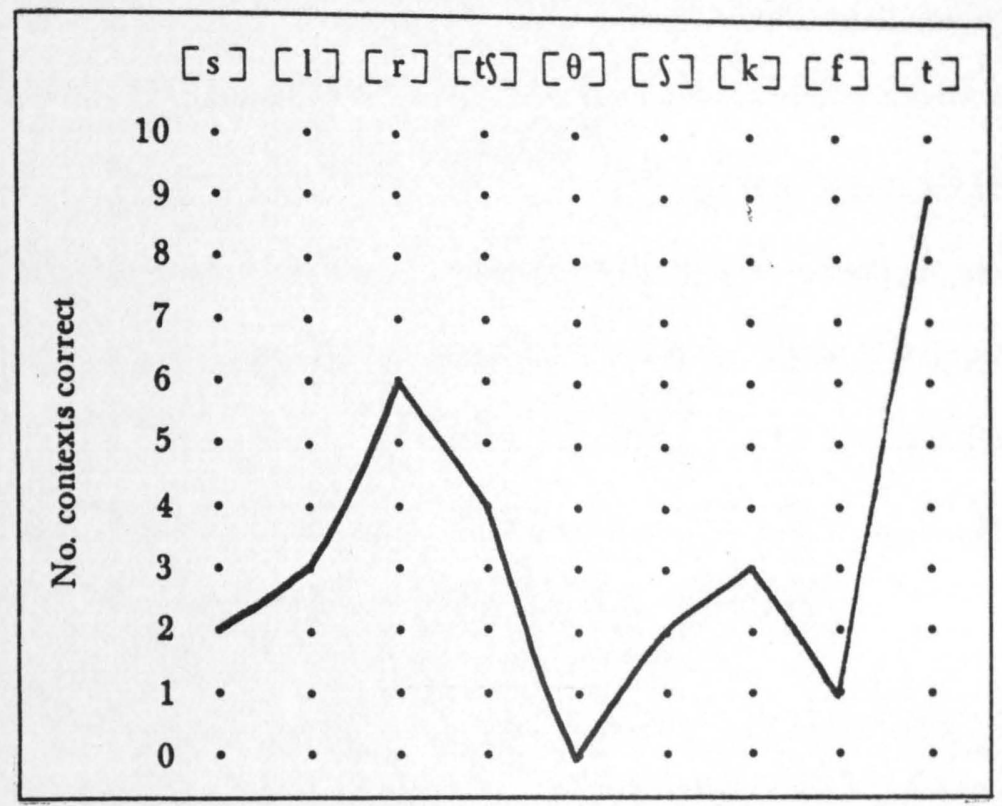

Figure 3. Subject B pre-test phonetic profile.

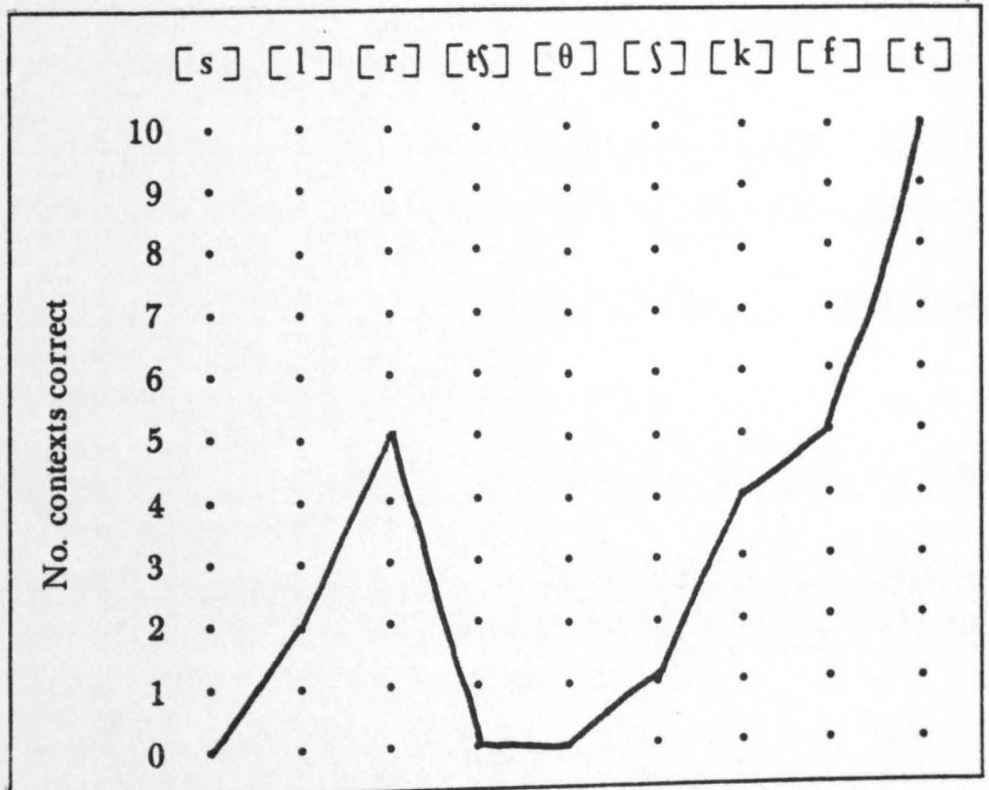

Figure 4. Subject B post-test phonetic profile. 
The results in Tables III and IV show that some growth in articulation performance occurred for both subjects, with more growth shown by Subject B (sensory-motor) than Subject A (auditory-stimulus). It should be noted there was a discrepancy between Subject A's and Subject B's baseline data. Subject A began treatment with less percentage correct, which revealed that, in fact, it was possible for him to make greater gains than Subject B. This indicated that initially Subject B's ability level was higher than Subject A's.

\section{Discussion}

Although the results showed relatively little difference between overall articulation growth, some comments can be made relative to this project.

The Developmental Test of Articulation (Hejna, 1955) tests overall phoneme proficiency in words in the three positions: initial, medial, and final. Neither subject performed particularly well in this test. Subjects A and B made minimal growth changes of 11.3 and 2.22 per cent, respectively. In looking at these changes it appears neither management method was particularly influential in improving the subjects' overall articulation ability.

A Screening Deep Test of Articulation (McDonald, 1968) tests overall articulation ability with the frequently misarticulated phonemes of $/ \mathrm{s} /, / 1 /, / \mathrm{r} /, / \mathrm{g} /, / \theta /, / \mathrm{S} /, / \mathrm{k} /, / \mathrm{f} /$, and $/ \mathrm{t} /$ in releasing and arresting positions in paired words. There are approximately ten phonetic contexts for each phoneme which yields ninety paired words. Subject A's (auditory-stimulus) percentage of growth change was 
greater than Subject B's (sensory-motor) on this test, although their final performance was equal. These results were somewhat unexpected because Subject B did not perform as well on this task. A possible explanation is that on the day of post-testing, Subject B did not appear to be motivated to perform. It should be noted further that Subject B did not appear motivated to perform the tasks during most management sessions; he would attempt to initiate conversations to direct the clinician away from management. Subject A's growth rate (+14.86 per cent) may indicate there was indeed transfer and generalization from the articulation management for $/ f /$ to the other phonemes tested on A Screening Deep Test of Articulation (McDonald, 1968).

As to the /f/ stimulus words in the three positions on The Developmental Test of Articulation (Hejna, 1955), Subject A's pre-test revealed misarticulation of $/ f /$ in all three positions. At the time of post-testing, misarticulation remained in the initial and final positions, but not in the medial position. This shows some improvement was made in the articulation of $/ f /$. Subject $B$ made no change, with correct articulation in the initial and medial positions and misarticulation in the final position at the time of pre- and post-testing. Analysis of The Deep Test of Articulation (McDonald, 1964a) for /f/ revealed no correct articulation by Subject $A$ in either the releasing or arresting position at the time of pre-testing and just one correct production in the arresting position at the time of post-testing. Since Subject A received the auditory-stimulus method, it appears little, if any, generalization occurred in articulation competency for the target sound /f/ in the sensory-motor mode of presentation. This 
is understandable in that Van Riper approaches sounds in isolation and McDonald approaches sounds in various phonetic contexts. Throughout clinic sessions Subject A appeared to have difficulty with sound blending skills, which is essential in the sensory-motor method.

Subject B's per cent of change as measured by The Deep Test of Articulation (McDonald, 1964a) revealed considerable improvement (36.6 per cent) in articulation competency for $/ f /$. This change, in part, could be that /f/ proficiency had generalized to various phonetic contexts. It also should be noted this subject was more aware of what was expected on the task, since he had received management in the sensorymotor approach and showed no difficulty with sound blending.

Both subjects made improvement in percentage of growth change for the list of twenty / $\mathrm{f} /$ words. Marked improvement was made by Subject B (62.5 per cent) and moderate improvement was made by Subject A $(27.7$ per cent). The clinician suspects such gains were made because she modelled each word; whereas, in all other tests, pictures were presented without a model. The subjects made use of visual and auditory cues, not only in the list of twenty words but also continually throughout management.

To this listener, intelligibility did not improve from pre- to post-testing in conversation samples for either subject. Additionally, Subject A appeared more intrinsically motivated with tasks presented to him during clinic sessions, although his gains were no greater than that of Subject B.

In conclusion, for these two subjects the sensory-motor method seemed to be more effective in correcting the misarticulated sound /f/ 
and the auditory-stimulus method more effective in changing overall articulation abilities. These conclusions are written cautiously in that management only lasted approximately six weeks. With a longer period of time for management and consideration of maturational factors, the results may have differed. 


\section{CHAPTER V}

\section{SUMMARY AND IMPLICATIONS}

\section{Summary}

The purpose of this project was to examine two methods of management for articulation and to evaluate whether one method was particularly more effective than the other. The two methods investigated were the auditory-stimulus (Van Riper, 1972) and the sensory-motor (McDonald, 1964a) approaches. The subjects were twin males with functional articulatory disorders. Subject A received the auditory-stimulus approach and Subject B the sensory-motor approach; each received the same preand post-tests in order to analyze whether one of the two different management approaches was more effeetive.

Evaluation of the pre- and post-test data revealed some apparent differences in percentage of growth change. Both subjects improved their overall articulation proficiency with Subject B showing greater improvement than Subject A.

This clinician feels the single most important factor clinically was the subjects' articulatory performance in conversation samples. Even though the $/ f /$ phoneme production and articulation ability improved as measured by several articulation assessment instruments, the intelligibility in conversational speech did not, which is of primary importance to communicating with others. 
To summarize, one can say articulation proficiency improved somewhat in testing situations.

\section{Implications}

In continuing management and this research, there are several factors to consider. First, one would want to continue management to determine if, in fact, the cautiously written conclusions were valid. If they were not, one would want to reexamine and make new conclusions.

Secondly, maturation would help in continuing management since many articulation errors spontaneously disappear in time.

Thirdly, with continued management motivational factors hopefully would change for the better in that the subjects would have become more experienced with the tasks presented. Also, it would be to the clinician's advantage to lessen the amount of time in clinic sessions and increase the number of days seen per week since the subjects appeared to have a short attention span.

More training time appears necessary in implementing the sensorymotor management approach for because of the short length of this study one does not know whether generalization would have occurred if management had lasted for a longer period of time.

This project feasibly could be continued in the public school setting. One can implement either or both of these two management approaches with children accordingly. 
HEJNA, ROBERT F., Developmental Articulation Test. Madison, Wisc.: College Printing and Typing (1955).

McDONALD, EUGENE T., A Screening Deep Test of Articulation. Toronto, Ontario: Stanwix House (1964a).

McDONALD, EUGENE T., Articulation Testing and Treatment. Toronto, Ontario: Stanwix House (1964b).

McDONALD, EUGENE T., A Deep Test of Articulation. Toronto, 0ntario: Stanwix House (1968).

McDONALD, EUGENE T., and McDONALD, JAMES M., Norms for the Screening Deep Test of Articulation based on a longitudinal study of articulation development from beginning kindergarten to beginning third grade. ESEA Title III (1974).

MECHAM, M., JEX, J., and JONES, J., Utah Test of Language Development. (rev. ed.) Salt Lake City: Communication Research Associates (1967).

STETSON, R. H., Motor Phonetics: A Study of Speech Movements in Action. Amsterdam: North Holland (1951).

VAN RIPER, CHARLES, Speech Correction: Principles and Methods. Englewood Cliffs, N.J.: Prentice-Hall (1972). 


\section{APPENDIX A}

SUBJECT A

I. To discriminate between $/ \mathrm{f} /$ and other consonants in isolation.

II. To correctly produce /f/ in isolation modelled and unmodelled ten times in a row.

III. To correctly produce /f/ in the initial, medial, and final positions in nonsense syllables modelled and unmodelled ten times in a row.

Initial: $f i, f a, f e, f u, f o, f(x, f \varepsilon, f r, f I, f \wedge$.

Medial: ifi, afa, efe, ufu, ofo, $\boldsymbol{x} \boldsymbol{x} \boldsymbol{x}, \varepsilon f \varepsilon, u f v$, I $\mathrm{I}, \boldsymbol{\wedge} \mathrm{f} \wedge$.

Final: if, af, ef, uf, of, $\boldsymbol{e f ,} \in f$, uf, If, ^f.

IV. To correctly produce /f/ in the initial, medial, and final positions in words modelled and unmodelled ten times in a row, e.g., fork, elephant, leaf.

V. To correctly produce /f/ in sentences modelled and unmodelled ten times in a row.

1. Sentences were elicited by the clinician and by the use of pictures. 


\section{APPENDIX B}

\section{SUBJECT B}

I. To heighten the child's responsiveness to the patterns of auditory, proprioceptive, and tactile sensations associated with the overlapping ballistic movements of articulation (McDonald, 1964b).

A. To imitate bisyllables composed of correctly articulated consonants using varying stress patterns:

1. To imitate bisyllables composed of consonants $/ \mathrm{m} /, / \mathrm{n} /, / \mathrm{p} /, / \mathrm{h} /, / \mathrm{b} /, / \mathrm{d} /$, and $/ \mathrm{t} /$, each followed by vowels with equal stress on each syllable.

2. To describe which parts of his mouth touched and the direction of tongue movement for each bisyllable.

3. To imitate bisyllables composed of consonants $/ \mathrm{m} /, / \mathrm{n} /, / \mathrm{p} /, / \mathrm{h} /, / \mathrm{b} /, / \mathrm{d} /$, and $/ \mathrm{t} /$, each followed by vowels (a, i, e, o, u, $\boldsymbol{x}, \varepsilon$, $I, v, \hat{\text { ) }}$ with an iambic stress pattern, e.g., /mimi'/.

4. To describe which syllable was stressed.

5. To imitate bisyllables with consonants $/ \mathrm{m} /, / \mathrm{n} /, / \mathrm{p} /, / \mathrm{h} /, / \mathrm{b} /, / \mathrm{d} /$, and $/ \mathrm{t} /$, each followed by vowels (a, i, e, o, u, $x, \varepsilon, I, v$, ^) with a trochaic stress pattern, e.g., /mími/.

6. To describe which syllable was stressed.

7. To imitate bisyllables composed of the same consonant and two vowels using equal, iambic, and trochaic stress patterns, e.g., /mimo/, /mimoó, and /mimo/.

8. To imitate bisyllables composed of two consonants and the same vowel with equal, iambic, and trochaic stress patterns, e.g., /mana/, /pata/,/mana'/, /pata'/,/mána/, and /páta/. 
9. To imitate bisyllables composed of two different consonants and two different vowels with equal, iambic, and trochaic stress patterns, e.g.,/máni/, /pati/, /manil/, /patí/,

B. To imitate trisyllables composed of correctly articulated consonants with varying stress patterns:

1. To imitate trisyllables composed of the following consonants $/ \mathrm{m} /, / \mathrm{n} /, / \mathrm{p} /, / \mathrm{h} /, / \mathrm{b} /$, $/ \mathrm{d} /$, and $/ \mathrm{t} /$, each followed by vowels (a, $i$, e, $u, 0, x, \varepsilon, v, I, \wedge)$ wi.th equal, iambic, and trochaic, and middle stress patterns, e.g., /mimimi/,/mimimi/,/mimimi/, and
/mimimi/.

2. To imitate trisyllables composed of varying vowels, using equal, iambic, trochaic, and middle stress patterns, e.g., /mimamo/, $/$ mimamo'/, /mímamo/, and /mimámo/.

3. To imitate trisyllables composed of varying consonants and the same vowel, each with equal, iambic, trochaic, and middle stress patterns,, e.g., /manapa/, /manapa//, /mánapa/, and /manápa/.

4. To imitate trisyllables composed of varying consonants and vowels, each with equal, iambic, trochaic, and middle stress patterns, e.g., /manipo/, /manipo'/, /manipo/, and /manípo/.

5. To imitate trisyllables composed of varying consonants, including both error and non-error consonants and vowels, each with equal, iambic, trochaic, and middle stress patterns, e.g., /finapo/, /napofil/, /fínapo/, and /nafipo/.

II. To reinforce the child's correct articulation of his error sound (McDonald, 1964b).

(Explanation: Select a sound which is correct in at least one phonetic context of The Deep Test of Articulation (McDonald, 1968). For Subject B, the error sound is correct in the following two contexts, /brushfive/ and/watchfork/. This indicates that 
correct production of the error sound occurs in the releasing position.)

1. To produce/brushfive/ and /watchfork/ at a slow rate. (Explanation: This reinforces the correct sensory-motor pattern.)

2. To produce/brushfive/ and/watchfork/ with equal, iambic, and trochaic stress patterns.

III. To facilitate the correct articulation of the sound in systematically varied phonetic contexts (McDonald, 1964b).

A. To produce / $\mathrm{f} /$ in paired words using / brush/ and/watch/ with releasing/f/ words followed by varying vowels, e.g., brushfit, brushfall, brushfold, brushfate, brushfood, brushfall, brushfold, brushfate, brushfuzz, and watchfit, watchfeed, watchfoot, watchfed, watchfat, watchfood, watchfall, watchfold, watchfate, watchfuzz.

B. To produce / $\mathrm{f} /$ in additional word combinations and sentences.

1. To produce /f/ in various word combinations of words with arresting $/ S /$ and $/ \mathrm{t} /$ and releasing /f/ for example: wash fun, pitch fee, beach fade, bush feed, mash fair, cash fuss, and catch fire.

2. To produce /f/ in various sentence combinations using the arresting $/ S /$ and $/ \mathrm{t} /$ and releasing /f/ for example:

a. Rover can catch fine.

b. I can teach fair.

c. We wash feet.

d. Pitch for me.

e. Search five times for Rover. 